\title{
Dynamic Analysis of Barriers to Entry as a Task for an Intelligent Tool
}

\author{
Maria A. Mach \\ University of Economics, Wroclaw, Poland \\ mach@manager.ae.wroc.pl
}

\begin{abstract}
The paper addresses the problem of dynamic analysis of barriers to entry in a chosen market. The role and importance of such analysis in enterprise strategy is explained. As a solution to the problem, the use of an intelligent tool is proposed. The tasks that such a tool should be able to perform and the expectations connected with such a tool are pointed out. Next, an architecture of an intelligent tool is proposed. The main components of the tool are presented and discussed. Problems to be solved during construction process of the tool are also pointed out. The paper also shows direction for future research concerning dynamic analysis of barriers.
\end{abstract}

Keywords: barriers to entry, intelligent tools, heterogeneous data sources, temporal analysis.

\section{Introduction}

Many factors that should be taken into account while discussing enterprise strategy exist in the economic environment of an enterprise. In one of the best known models of this environment, by M. E. Porter (1999), the environment consists of five forces: barriers to entry to a market space, the lobby of buyers, the lobby of suppliers, substitutes, and fight between market rivals. It is a very simplified model, nevertheless it shows that barriers to entry constitute one of the main factors that are to be analysed while formulating enterprise strategy, all the more Porter is not the only author stressing the importance of this factor. It is also important that barriers to entry - as other elements of economic environment - change dynamically, so it becomes necessary to take into consideration their temporal aspect.

The main goal of the paper is to formulate the problem of dynamical analysis of barriers to entry and to analyse it as a task for an intelligent tool, that is, the tool that aids inference.

The rest of the paper is organised as follows. Section 2 contains definitions from the literature of barriers to entry. It also contains a short explanation of types of barriers to entry as well as their role in enterprise strategy. Section 3 is devoted to the problem of dynamic analysis of barriers to entry. In the next section we define the tasks that should be performed by an intelligent tool that is to help decision makers in the dynamic analysis of barriers to entry. We also include in that section a short survey on some of the

Material published as part of these proceedings, either on-line or in print, is copyrighted by Informing Science. Permission to make digital or paper copy of part or all of these works for personal or classroom use is granted without fee provided that the copies are not made or distributed for profit or commercial advantage AND that copies 1) bear this notice in full and 2) give the full citation on the first page. It is permissible to abstract these works so long as credit is given. To copy in all other cases or to republish or to post on a server or to redistribute to lists requires specific permission from the publisher at Publisher@InformingScience.org solutions that can be found in the literature, and analyse them in the context of the problem defined. In section 5 we present an initial sketch of a tool that would help the decision makers to perform a dynamic analysis of barriers to entry. Finally section 6 is devoted 
to conclusions and future research directions.

\section{Definition and Types of Barriers to Entry: The Role of Barriers in Enterprise Strategy}

Many definitions of barriers to entry can be found in the literature. The simplest and the most intuitive of them is the one saying, that a barrier to entry means everything that makes entry to a branch or market space difficult for economic entities ("Barriers to Entry", 1994).

Next, Stigler, Baumol, and Willig define a barrier to entry as an expense that has to be borne by an enterprise to enter the market space, but that does not have to be borne by economic entities already operating on the market ("Barriers to Entry", 1994). Their definition is similar to the one of Gilbert, who defines a barrier to entry as "a rent that is derived from incumbency" (Gilbert, 1989). Finally, there is a definition used by Bain, who - in his classic book Barriers to new competition: their character and consequences in manufacturing industries defines a barrier to entry as a level, to which incumbents can elevate their prices above the minimal average cost, without encouraging new enterprises to enter the market (Bain, 1993).

The fact that there are so many definitions of barriers to entry can be seen in a way as derived from the fact there are so many different kinds of barriers. A diversity of classifications concerning barriers to entry is found in the literature. We will quote here the classification proposed by economists from British Office of Fair Trading ("Barriers to Entry", 1994).

In their study devoted to barriers to entry ("Barriers to Entry", 1994), the economists from British Office of Fair Trading, taking into account the type of cost that has to be borne by an enterprise wishing to enter the market, distinguished the following types of barriers:

a) absolute cost advantage that an incumbent possesses over a potential entrant. One can talk about such barrier if future (potential) costs per unit of production of a potential entrant are generally higher than those of the incumbents. The main sources of this barrier are patents, resources control, monopolisation of specific knowledge (so-called know how);

b) strategic advantage - here we can distinguish the following groups of barriers:

- sunk costs and economies of scale - the necessity to bear the costs of the entry, that would not be paid off in case of failure; the necessity of entering on the big scale if the venture is to bring profits;

- product differentiation and advertising. In the simplest case it means that the product space is filled with so many brands, that a potential rival has not enough place to enter and to get back his sunk costs. Advertising at a great scale is expensive, not every entrant can afford it. It must be said here that product differentiation does not always generate barriers to entry, nevertheless some of them can be linked with it;

- capital requirements;

c) vertical foreclosure - for example exclusions, supply contracts. These are practices because of which rivals can not access important production means or can not access clients (consumers) on equal rights (that is, within the same conditions as incumbent firms);

d) predatory behaviour. This concerns pricing practices which consist of reducing prices in the short term to eliminate rivals from the market or to discourage potential entrants from 
entering the market space. An incumbent having enormous financial resources can threaten a rival suffering from financial deficiency.

The goal of barriers to entry analysis could be, among others, an attempt to assess enterprise market position (present or future). Such kind of analysis is performed for example by antitrust offices.

What role do the entry barriers play in enterprise strategy? It is obvious that the knowledge on what kind of barriers our enterprise creates or could create, as well as the knowledge on barriers that can be possibly met by our firm, will significantly determine the process of elaborating corporate strategy. It is therefore worth thinking over the aspects in which barriers to entry affect enterprise strategy.

In the simplest model, enterprise strategy means a choice of (among others) (Mazurkiewicz, 1997):

a) markets and products: a height of barriers can discourage or encourage to conduct an expansion on the given market,

b) capital resources: an amount of capital required can constitute an effective barrier discouraging from expansion.

Next, Obloj (1997) mentions - as the main elements of enterprise strategy - a so-called strategic advantage which can be obtained due to an ability to build barriers to entry that are adequate to market situation.

Last, but not least, barriers to entry are mentioned explicitly in the already classic model of enterprise environment, namely the model of five market forces by Porter (1999). This author distinguishes in the environment of an enterprise the following elements:
a) barriers to entry,
b) suppliers,
c) buyers,
d) substitutes,
e) rivalry between competitors.

Summing up, it can be easily noticed that, while working on its strategy, an enterprise has to gain knowledge about:

a) how barriers to entry were behaving in the past (historical analysis),

b) what is the current state (the current state diagnosis),

c) how will barriers to entry behave in the future (prognostic element),

d) what are (if any) legal and economic possibilities to create and to overcome barriers to entry in the existing economical-legal system,

in order to adapt its strategy to the situation.

\section{Dynamic Analysis of Barriers to Entry}

The diversity of possible barriers to entry causes their importance as a problem or economic factor affecting enterprise operations. Moreover, barriers to entry affect operations (strategies) of both enterprises already operating in the market, which want to protect their market position, as well as enterprises planning to enter certain markets, while barriers may make the entry more dif- 
ficult, cause a delay or even make entry impossible. Therefore, conducting an analysis of barriers to entry is a very important and useful task. It becomes even more important if the analysis is performed dynamically, since barriers to entry - as each of the elements of enterprise environment are not steady, but change in time. For example, changes the type of existing barriers, some of barriers appear and some disappear, also barriers' strength (height) changes. Therefore, it seems necessary to construct a tool that would enable performing a dynamic analysis of barriers to entry. This kind of task requires using suitable description formalisms, adequate for the phenomenon being analysed, and is connected with the problem of integrating knowledge from heterogeneous sources.

What makes dynamic analysis of barriers to entry so important?

First, basic structural features of the market can change (Bain, 1993) and this in turn can cause changes in the entry conditions and in barriers.

Second, each entry to a market occurs in time - longer or shorter ("Barriers to Entry", 1994). It is not a single, momentary action; it is extended over a period of time. Speaking in temporal logic terms, it is an event occurring over a time interval and not at a time point. Moreover, it should be taken into account that time granularities for different industries are not the same, in other words, in some branches, because of their particular features, entries are quicker, in other ones - entries are slower.

Third, putting entries to a market in a time context allows their historical analysis, that is, an analysis of a history of entries end exits in an industry, a history of profit trend in an industry, efficiency and duration of entries in the past, changes in market conditions over a period of time etc. ("Barriers to Entry", 1994). Such analysis is indispensable, for example, to foresee efficiency of currently planned entry.

Fourth, time differences appear not only between entries in different industries, but also within the confines of one market: entry conditions can change from one season to another - it is a socalled temporal feature of the market (Whish, 1993).

\section{Postulates for an Intelligent Tool Aiding at Dynamic Analysis of Barriers to Entry}

To the best of our knowledge, in the literature there is no complete description of a problem of dynamic analysis of barriers to entry, moreover, one can notice that there is a lack of proposals to solve this problem with the aid of intelligent tools. Instead, there are known models of the problem built from the economic point of view.

First, and at the same time, the simplest temporal model of barriers to entry analysis assumes, that the timeline including the period of analysis is divided into two sub-periods: before and after an action of entering the market by a firm (Gilbert, 1989). The analysis is performed for each of subperiods separately, and so is the description of the most important market features (including barriers to entry). In this way both sub-periods can be compared to each other.

The second model described in the literature and one that can be applied to temporal analysis of barriers to entry is Bernheim's model first described in 1984 (Gilbert, 1989). The model describes branch dynamism in terms of general profit functions and cost functions, where costs are understood as firm's expenses needed to make entry difficult for rivals.

While trying to build a coherent description of barriers to entry, a description that would allow performing an analysis of those barriers, we face the basic difficulty consisting of the fact, that 
barrier groups present different kinds of features. Therefore constructing a coherent description of so many different features is a serious problem, which can be even treated as a kind of challenge.

If we take as a starting point the classification of barriers proposed by British Office of Fair Trade ("Barriers to Entry", 1994), which constitutes a throughout description of barriers in the context of their role in enterprise strategy, and if we also take into account barrier definitions and barrier sources, we can qualify each group of barriers as a feature to describe. We propose the following qualification:

a) absolute cost advantage of an incumbent over an entrant firm: qualitative (descriptive) feature,

b) strategic advantage:

- sunk costs and economies of scale: quantitative feature,

- product differentiation and advertising: qualitative-quantitative (mixed) feature product differentiation is a descriptive, qualitative element, while advertising scale, as measured by expenses, is a quantitative element,

- capital requirements: quantitative feature;

c) vertical foreclosure - for example exclusions, supply contracts: descriptive (qualitative) feature,

d) predatory behaviour: qualitative feature.

As it can be easily seen, each type of barrier due to its specific characteristics will need a different description formalism. The question of choosing adequate formalisms we leave untouched for the time being. In the present state of our work, the most important thing is an observation that getting a coherent view of barriers to entry, before analysing them, is strictly connected with the problem of integrating knowledge coming from heterogeneous sources.

If we assume here that the analysis of barriers to entry will be performed by an intelligent tool, one can see the following tasks for such tool:

1. providing an appropriate description of barrier groups, that would respect their diversity and temporal aspect,

2. unifying the descriptions of barriers, which would allow further, more general inference here we face explicitly the problem of integrating knowledge from heterogeneous sources, because, as it was mentioned above, each group of barriers will need different description formalism,

3. allowing historical and dynamic analysis of barriers to entry to a market space,

4. diagnosing current state (what are current entry barriers), and forecasting (what will be entry barriers in the future).

Now, when we pointed out the tasks for an intelligent tool for dynamic analysis of barriers to entry, it is worth thinking which of the solutions that can be found in the literature could be appropriate for those tasks. Of course, some modifications of existing solutions could be necessary.

We have already mentioned that after formalising barriers descriptions we face the problem of their integration, as they are heterogeneous. Therefore we will now present some of the approaches to integration proposed by different authors and we will consider their adequacy to the problem formulated in our paper. 


\section{Proposal by Wiederhold, Jajodia and Litwin}

The above authors take up the problem of unifying temporal information from temporal bases characterised by different time granularities. Generally speaking, they divide processing of temporal data with different granularities into three stages:

a) collecting new data,

b) converting data into histories - during this stage one has to deal with unification problem,

c) searching for useful information by queries.

Converting data into histories is the critical stage. The authors proposed a special history operator, $\mathrm{H}$, which allows to specify each transformation. The second operator introduced by the authors is the operator I, giving information about an object in a given time point, therefore it is the most often used to get current information (information about current state). The detailed formalisation of the proposal by the mentioned authors can be found in (Wiederhold, Jajodia \& Litwin, 1991). This solution could be useful for our purposes, because it includes a mechanism for unifying temporal information, as well as the operator returning the present value of a parameter therefore it could be probably possible to unify information about changes of different barriers in time and to get a diagnosis of current state.

\section{Proposal by Subrahmanian}

In his paper, Subrahmanian (1994) proposes an amalgamation logic for integrating knowledge from heterogeneous knowledge bases. The logic is based on a group of logics that are an extension of logical programming, in which atoms are expressed explicitly by values that can be perceived as confidence coefficients, certainty factors etc. (Adali \& Emery, 1995). This group of logics, called annotated logics, was introduced in the late eighties by Subrahmanian as logical frame for deductive databases, containing incoherent, conflicting or contradictory information. The annotated logics lack algebraic semantics (Bowers, Lewin \& Pigozzi, 2000).

Most generally speaking, amalgamating knowledge bases means that there are some local knowledge bases and a meta-base (in some papers this meta-base is called mediator) that define, among others, how to merge local knowledge bases. This meta-base has to be described in a language that will allow one to infer information about local bases and to manipulate them. The integrated knowledge, coming from meta-base, is called an amalgam. Subrahmanian's proposal has the following features:

- an user can work directly with an amalgam, and at the same time he can formulate queries concerning knowledge bases that "built" the amalgam,

- relationships between local knowledge bases semantics can be analysed.

The above solution allows for merging different knowledge bases and data structures (e.g. relational, object, spatial and temporal ones). In the context of the inference task that is formulated in our paper, a solution consisting of amalgamating knowledge bases has the following useful features:

a) amalgamation logic allows for integrating different data structures, therefore different kinds of barriers descriptions can be taken into account,

b) amalgamation logic allows working directly with barriers descriptions (and thus getting information about each barrier) as well as working with a general, unified information (thus getting a picture of barriers as a whole, which can be a starting point for further inference). 


\section{Proposal by Adali and Emery}

Adali and Emery propose an MPE - Mediatory Programming Environment (1995) that is understood by them as an interpreter, that is, to process programs written in a mediatory language and to communicate with external programs. In their paper they refer to the conception of mediators, proposed by Wiederhold (see e.g. Wiederhold, Jajodia \& Litwin, 1991; Wiederhold, 1992;

Wiederhold, 1999). They treat a mediator as a program written in a special language, operating on information coming from different sources. Usually those sources are applications and program packages existing before.

Mediatory programming environment could enable to describe barriers to entry using commonly known tools (e.g. parameters written in a spreadsheet, text information, etc.), which in turn would allow not only to grasp the diversity of those barriers, but would also have a practical aspect, because the tools already existing in an enterprise could be used.

\section{Proposal by Hahn and Romacker}

The family of SYNDIKATE systems, presented in (Hahn \& Romacker, 2000) has been developed to understand natural language texts, to acquire from those text knowledge in the form of facts, complex sentences and assessment propositions, and to move this knowledge to formal representation structures, that is to a text knowledge base. Therefore, taking into account the main goal for which SYNDIKATE systems were created, they could enable to generate a text knowledge base about barriers to entry, on the basis of - for example - economy experts.

\section{Proposal by Liberatore and Schaerf}

The authors Liberatore and Schaerf (2000) take up the problem of integrating knowledge from different knowledge bases. They distinguish three main conceptual approaches to the problem:
a) belief revision,
b) merging,
c) update.

They present a BReLS system that is a framework in which the three approaches meet. Thanks to such combination, it is possible to formalise complex domains where information can have a different degree of reliability and can appear in different time points.

Knowledge in BReLS system is expressed via prepositional formulas, supplied by positive integers, representing certainty level. Time in turn is expressed via syntax borrowed from Sandewall's work (1994). There are two kinds of models in the system: static and dynamic ones. As BReLS enables to formalise complex domains with different kinds of information (certain and uncertain) appearing in different time points, and barriers to entry constitute with no doubt such a domain, therefore it seems that the system could be useful for the task of dynamic analysis of barriers to entry.

Summing up it should be noticed that actually the majority of solutions, concerning integration of knowledge from heterogeneous sources, one could try - after some modifications, if needed - to use for dynamic analysis of barriers to entry. Of course, in the literature there are much more solutions concerning knowledge integration (including temporal knowledge), both in theoretical and practical aspects. The goal of this section was not to present them all, but to indicate a possibility of using some of them to the problem formulated at the beginning. Therefore we have chosen only those solutions that seemed to us the best suited for the task. 


\section{Architecture of an Intelligent Tool - an Initial Proposal}

In previous section, we briefly studied existing solutions concerning heterogeneous knowledge integration, and we examined the possibility of using them for analysing barriers to entry in the context of tasks for an intelligent tool. In this section we present a rough sketch of a solution that would be - in our opinion - adequate to the problem discussed throughout the paper.

Our solution is based in a way on the proposal by Adali and Emery (1995) quoted before. Let's briefly recall it: they proposed a so-called mediatory programming environment, where mediator is a some kind of pier between an user and different data and knowledge repositories, providing the user with a coherent description of reality captured by those sources.

A scheme of mediatory programming environment is presented in Figure 1.

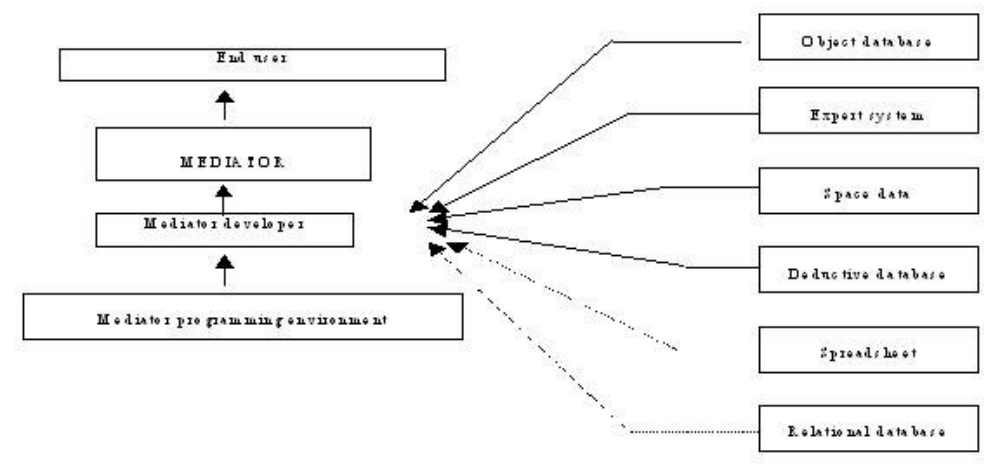

Fig. 1. A conception of mediators. Source: (Adali \& Emery, 1995).

In Figure 2 an initial conception of a solution proposed by us is presented.

As it can be seen in Figure 2, the starting point is to construct descriptions of each group of barri-

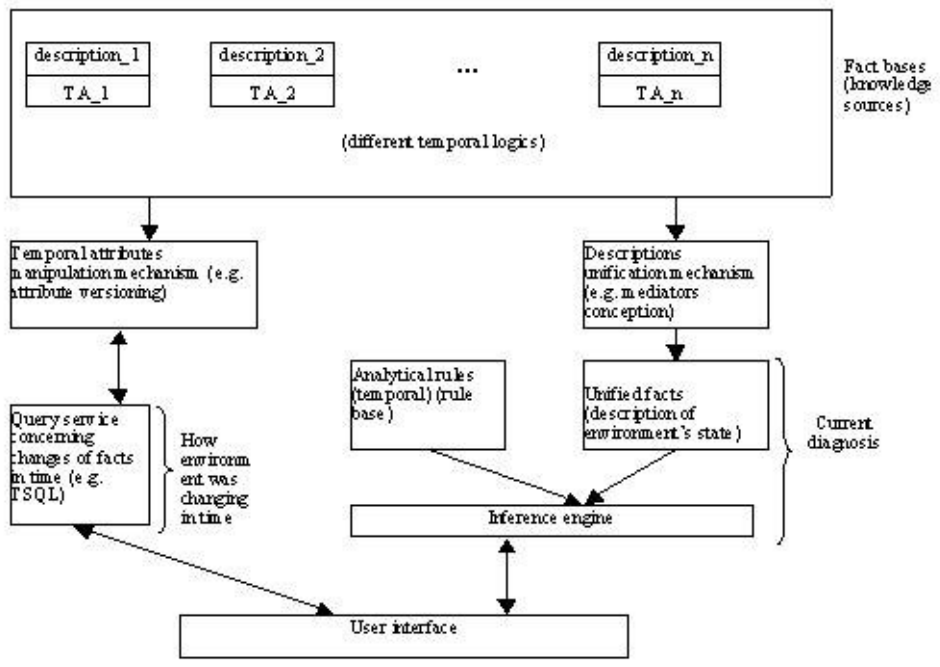

Fig. 2. A conception of an intelligent tool aiding dynamical analysis of bamiers to entry to a market space. Source: Own elaboration 
ers to entry. As was stated in a previous section, the question of choosing adequate description formalisms we left untouched for future research. Therefore now we will not get into details. We would only like to stress that - taking into account the dynamism of barriers to entry - it would probably be purposeful to describe them using different, adequate temporal logics, chosen according to barriers' characteristics (qualitative and quantitative barriers). As is commonly known, there are many temporal logics (see e.g. Hajnicz, 1996; Klimek, 1999). Therefore we will not focus here on the formalism choice, although it is extremely important. On the introductory stage of constructing our solution, it is too early to choose temporal formalisms definitely. Having described each group of barriers to entry we have the problem of representation solved, but there still remains unsolved the problem of inference. We agree with authors Brusoni, Console, Pernici and Terenziani (1994) that for proper inference about temporal information we have to unify them properly and adequately. And again it must be said here that there exist many approaches to the problem of integration of heterogeneous knowledge, therefore we have to elaborate the way of choosing a method suitable for our needs and for our inference task. The conception of mediators, presented in Figure 2, is only an example, not our definitive choice.

After unifying barriers' descriptions, we get a unified knowledge base. We then propose to overlap on it a base of analysis rules, which would lead, after using an appropriate inference engine, to a diagnosis of current state (that is, what are current barriers to entry). The construction of inference engine is an open question. The work on our conception is at a so early stage, that we knowingly do not touch this problem; we only indicate its importance.

Our next idea is to treat each description of barrier groups as fact bases, which also - as barriers change - will change in time. If we capture those changes, it would be possible to get information about changes in economic environment in time (or more precisely, about changes of one of the elements of the environment). Of course, the mechanisms providing such information, illustrated in Figure 2, such as attribute versioning or TSQL for query processing, are only the initial, exemplary proposals, needing verification.

Summing up it must be noticed, that taking into account the amount and the importance of tasks for an intelligent tool aiding at dynamical analysis of barriers to entry, the elaboration of such tool still needs lots of studies and work. All that was said above about the tool must be treated only as a starting point for further investigation.

We are convinced that it is worth mentioning here the LaTeR system, described in (Brusoni et al., 1994). It is - according to its authors - a temporal knowledge server or a system for managing temporal knowledge that can be used by different kinds of applications. Heterogeneous temporal information, both quantitative and qualitative, is integrated using constraints network. Temporal inference is understood as data manipulation - information inserting and/or deleting - or constraint propagation. The prototype of LaTeR system was implemented in Prolog on Macintosh machine.

Brusoni et al. (1994) claim that unification of knowledge representation is the basis for inference process. We find this claim correct. Nevertheless, their system is not competitive to our proposal, because the authors of LaTeR say nothing about formalisms for representing temporal information. In our opinion, in a complete, elaborated system, information about those formalisms seems necessary. Moreover, the authors deal - again in our opinion - with temporal databases and database queries, not with temporal knowledge base. Such approach allows to get answers to queries in temporal database (after unifying it), but it does not give e.g. prognostic possibilities, which as it was already said - an intelligent tool for dynamic analysis of barriers to entry should have. 


\section{Conclusions}

We presented the problem of dynamic analysis of barriers to entry to a market space as a task which can be solved or may be attempted to solved, using intelligent tools. We stressed mainly the economic aspects of the problem and those of its features and those of its features that allow us to classify it as a task for an intelligent inferring system. We also made an attempt for sketching an initial proposal for solving the above problem in the light of artificial intelligence.

We analysed some solutions that can be found in the literature. We find such an analysis indispensable for developing our proposal, as we first have to know what was already done in the field of our interest, what needs to be done and what can be applied after slight modifications.

The model that we propose, after it is fully developed, can be applied to make strategic decision in an enterprise faster. And this in turn would allow gaining a "first-mover advantage" over other entrants. Such strategic behaviour fits into the "economy of speed" concept (Tvede \& Ohnemus, 2001) which allows an enterprise to achieve a high market share

Future research directions should include:

a) choosing adequate formal descriptions of barrier groups and proving the adequacy of descriptions chosen,

b) choosing a method for unifying the descriptions,

c) choosing a method for describing how the fact bases change in time.

We are currently working on the first of the above points and we are planning to continue our work on the remaining two points.

\section{References}

Adali, S., \& Emery, R. (1995). A uniform framework for integrating knowledge in heterogeneous knowledge systems. Proceedings of the Eleventh IEEE International Conference on Data Engineering, pp. 513-520.

Bain, J. (1993). Barriers to new competition: their character and consequences in manufacturing industries. USA: Augustus M. Kelley.

Barriers to entry and exit in UK competition policy. (1994). A report by London Economics for the Office of Fair Trading. OFTRP2, March 1994.

Bowers, S. E., \& Lewin, R. A., Pigozzi, D. (2000). An annotated logic defined by a matrix. Retrieved May 18,2000 , from http://www.mat.puc.cl/ rlewin/papers/paper_renato.pdf

Brusoni, V., Console, L., Pernici, B., \& Terenziani, P. (1994). LaTeR: A general purpose manager of temporal information. In: Raś Z. W., Zemankova M. (Eds.), Methodologies for Intelligent Systems. Proceedings of the ISMIS-94: $8^{\text {th }}$ International Symposium. Springer-Verlag.

Gilbert, R. J. (1989). Mobility barriers and the value of incumbency. In R. Schmalensee \& R. D. Willig (Eds.), Handbook of Industrial Organization (Vol. 1, pp. 475-535). Elsevier Science.

Hajnicz, E. (1996). Reprezentacja logiczna wiedzy zmieniajacej się w czasie. Akademicka Oficyna Wydawnicza PLJ, Warszawa (in Polish).

Hahn, U., \& Romacker, M. (2000). Content management in the SYNDIKATE system - How technical documents are automatically transformed to text knowledge bases. Data \& Knowledge Engineering, 35 (2), 137-159.

Klimek, R. (1999). Wprowadzenie do logiki temporalnej. Uczelniane Wydawnictwa NaukowoDydaktyczne AGH, Kraków (in Polish). 
Liberatore, P., \& Schaerf, M. (2000). BReLS: A system for the integration of knowledge bases. Proceedings of KR-2000: $7^{\text {th }}$ International Conference Principles of Knowledge Representation and Reasoning, 145-152. Morgan Kaufmann.

Mazurkiewicz, L. (1997). Strategie marketingowe firmy. Wydawnictwo Prywatnej Wyższej Szkoły Businessu i Administracji, Warszawa (in Polish).

Obloj, K. (1997). Strategia sukcesu firmy. PWE Warszawa (in Polish).

Porter, M. E. (1999). Strategia konkurencji. Metody analizy sektorów i konkurentów. PWE, Warszawa (Polish translation).

Sandewall, E. (1994). Features and fluents. Oxford University Press.

Subrahmanian, V. S. (1994). Amalgamating knowledge bases. ACM Transactions on Database Systems, 19 (2), 291-331.

Tvede, L. \& Ohnemus, P. (2001). Marketing strategies for the new economy. John Wiley \& Sons.

Whish, R. (1993). Competition law ( $3^{\text {rd }}$ ed.). Butterworth \& Co.

Wiederhold, G. (1992, March). Mediators in the architecture of future information systems. IEEE Computer, pp. 38-49.

Wiederhold, G. (1999). Mediation to deal with heterogeneous data sources. Proceedings of Interop'99, Zurich, LNCS Vol. 1580, pp. 1-16. Springer.

Wiederhold, G., Jajodia, S., \& Litwin, W. (1991). Dealing with granularity of time in temporal databases. Proceedings of the $3^{\text {rd }}$ International Conference on Advanced Systems Engineering, Trondheim, Norway, 15-15 May 1991, LNCS Vol. 498, pp. 124-140. Springer-Verlag.

\section{Biography}

Maria A. Mach Ph.D. is a faculty member of the Wroclaw University of Economics. Her research interests include knowledge management, artificial intelligence systems in marketing and banking, temporal representation and temporal intelligent systems. She authored and co-authored over 20 articles and book chapters concerning the above mentioned and other areas. 